\title{
Preface: Eighth Pacific Basin Conference on Adsorption Science and Technology
}

\author{
Shin R. Mukai ${ }^{1}$
}

Published online: 3 July 2019

(c) Springer Science+Business Media, LLC, part of Springer Nature 2019

The Eighth Pacific Basin Conference on Adsorption Science and Technology (PBAST-8) was scheduled to be held in Sapporo, Japan, during the period of September 3 to 6, 2018. Unfortunately, a severe earthquake hit Hokkaido early morning of September 6, and the first major "blackout" in Japan, which continued over $46 \mathrm{~h}$ even in certain parts of Sapporo, spread across the whole prefecture. This forced us to cancel the final day of the conference, along with the conference excursion. All the participants were seriously affected by this incident, and many of them had a hard time to return home. We deeply apologize for this unfortunate incident and hope that nobody was seriously hurt or injured.

PBAST is held every 3 years in one of the Pacific Basin countries. The aim of this conference series is to provide a platform so that researchers who are involved in the field of adsorption science and technology, especially those from the Pacific Basin region, can freely discuss and exchange ideas. This conference started in Kisarazu, Japan in 1997 and was followed by conferences in Australia (2000), South Korea (2003), China (2006), Singapore (2009), Taiwan (2012) and China (2015).

This was the second conference in Japan and it was our great honor and pleasure to have the founders of this conference series, Professor Katsumi Kaneko, Professor Duong D. Do and Professor Chang-Ha Lee as Plenary Lecturers of this conference. We also appreciate it that 5 Distinguished Professors leading the field of Adsorption Science and Technology, Professor Keith E. Gubbins, Professor Suresh Bhatia, Professor Krista S. Walton, Professor Yousheng Tao and Professor Hideki Tanaka, kindly accepted our offers to attend this conference as Keynote Lecturers. We also thank all the 147 participants who came all the way to Sapporo from 14 different countries.

Shin R. Mukai

smukai@eng.hokudai.ac.jp

1 Faculty of Engineering, Hokkaido University, Sapporo 060-8628, Japan
A total of 119 papers were submitted to this conference, which were presented as 3 Plenary Lectures, 5 Keynote Lectures, 51 Oral Presentations and 60 Poster Presentations. The papers were categorized into the following 7 fields:

(A) Fundamentals of Adsorption (Oral: 17, Poster: 9)

(B) Instrumentation for Adsorption Measurement (Oral: 2, Poster: 1)

(C) Chemisorption and Catalysis (Oral: 2, Poster: 4)

(D) Synthesis and Characterization of Novel Adsorbent Materials (Oral: 8, Poster: 20)

(E1) Adsorption for Energy Related Applications (Oral: 10, Poster: 13)

(E2) Adsorption for Bio-applications (Oral: 5)

(E3) Adsorption for Environmental Protection (Oral: 7, Poster: 13)

We believe that this conference was able to cover the full spectrum of fundamental research and applications of adsorption.

PBAST- 8 was supported by the following organizations and corporations:

Faculty of Engineering, Hokkaido University

Frontier Chemistry Center, Hokkaido University

Japan Society on Adsorption

The Suginome Memorial Foundation

Hiden Isochema LTD

MicrotracBEL Corp.

Osaka Gas Chemicals Co., Ltd.

Anton Paar GmbH

We are very grateful for the generous supports from these organizations and corporations. They really helped to get us through an odd situation caused by an extremely rare incident. 


\section{PBAST-8}

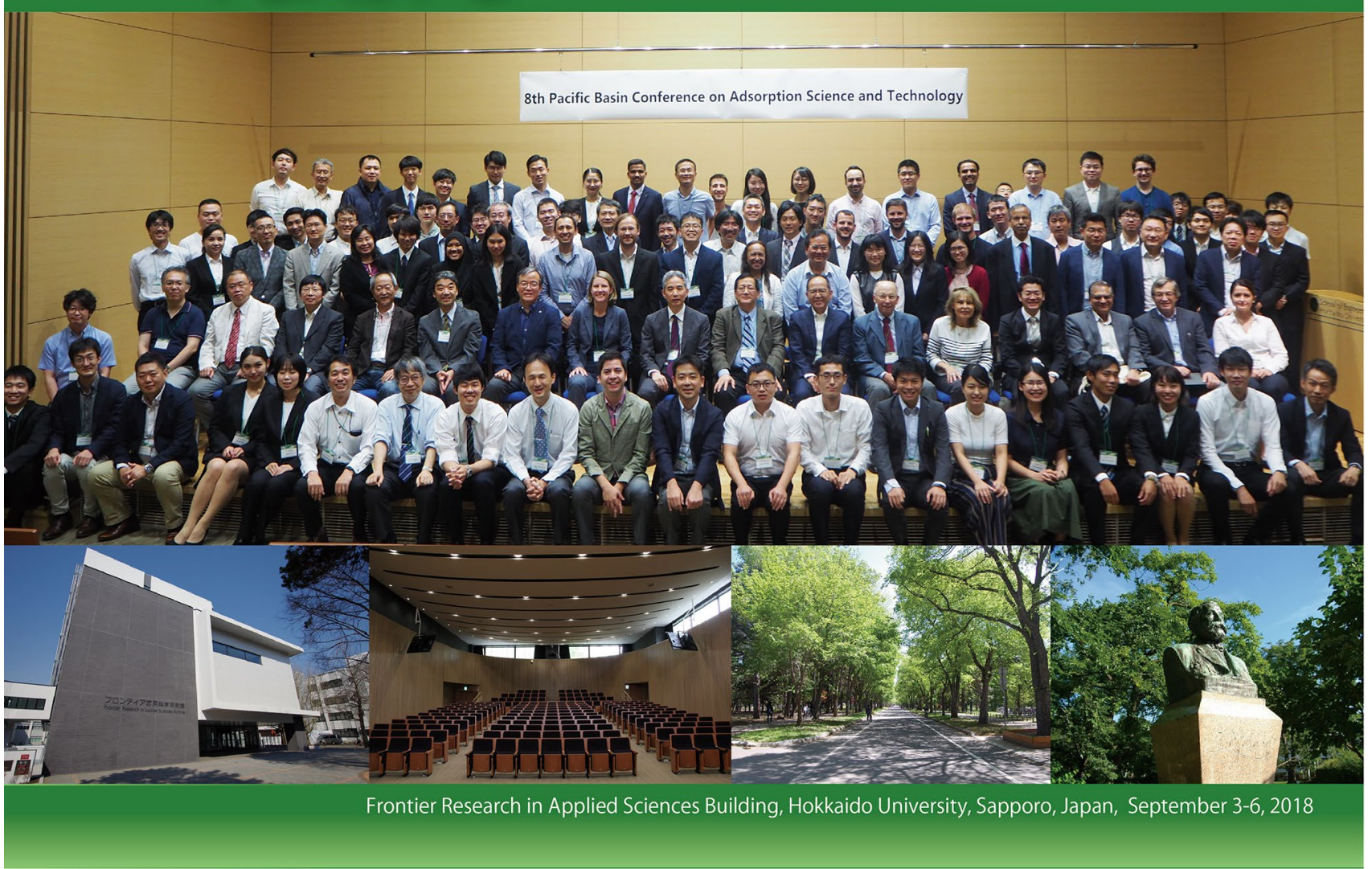

The conference chair is grateful to the International Advisory Committee and Organizing Committee who helped to prepare for and manage this conference. Special thanks go to Dr. Akira Endo, Professor Takahiro Ueda and Professor Shinichiroh Iwamura who devoted their time and energy to respectively serve as the Secretary, Program Chair and Treasurer of the Conference.

We appreciate it that many of the participants were willing to submit their paper to this Special Issue of Adsorption, even though the conference ended in an unconventional way. We also thank all of those who helped us in the reviewing process. We are also grateful to Professor Farooq Shamsuzzaman and Professor Akihiko Matsumoto for their support and guidance to compile this issue.
PBAST-9 will be chaired by Professor Fei-Yee Yeoh and will be held in Kuching, Malaysia in June 2021. We are very excited that a new country has joined this conference series. We have been informed that Kuching, Malaysia is free from earthquakes and surprisingly even from typhoons, which frequently affect nearby regions. We hope that many of the international adsorption community will attend this conference not only to gather latest information of adsorption science and technology, but also to experience the deep and rich culture of this region.

Publisher's Note Springer Nature remains neutral with regard to jurisdictional claims in published maps and institutional affiliations. 